\title{
“Eu não vou pedir permissão para ocupar": un análisis relacional de las disputas socio-urbanas en contexto de gentrificación
}

Carolina Cravero Bailetti ${ }^{1}$ Universidad Nacional de Rafaela

Resumen: Este artículo analiza desde una perspectiva relacional cómo los procesos de gentrificación fragmentan las luchas políticas generando conflictos sociales entre actores que manifiestan consignas semejantes y se expresan por el derecho a la ciudad y vivienda. Para ello observa cómo opera la dimensión étnica del habitus en tanto marcador social que reproduce las estructuras de poder simbólico y diferencia entre aliados y enemigos políticos de la gentrificación. De esta manera, el centro de la ciudad de Curitiba se vuelve territorio de disputas que revelan el componente racista de las denominadas políticas de "revitalización".

Palabras clave: gentrificación; habitus étnico; Curitiba; urbanismo; Brasil.

${ }^{1}$ Becaria posdoctoral del CONICET, Argentina. Doctora en Sociología por la UFPR, Brasil. Magíster en Investigación Educativa mención Socio-antropología por la UNC, Argentina. Profesora de Metodología de la investigación cualitativa y sociología de la Universidad Nacional de Rafaela, Argentina. 


\title{
“Eu não vou pedir permissão para ocupar": uma análise relacional das disputas socio-urbanas em contexto de gentrificação
}

\begin{abstract}
Resumo: O artigo analisa desde uma perspectiva relacional como os processos de gentrificação dividem as lutas políticas e geram conflito social ainda entre os próprios atores que expressam consignas semelhantes e se proclamam sobre direito à cidade e moradia. Para isso foram observadas as formas em que atua a dimensão étnica do habitus como marcador social que reproduz as estruturas de poder simbólico que separa entre parceiros e adversários da gentrificação. Assim, o centro da cidade de Curitiba torna-se território de disputa que revela o conteúdo racista das denominadas políticas de "revitalização".
\end{abstract}

Palavras-chave: gentrificação; habitus étnico; Curitiba; urbanismo; Brasil.

\section{"Eu não vou pedir permissão para ocupar": a relational review of urban disputes in gentrification context}

\begin{abstract}
This article analyzes from a relational perspective how the gentrification fragments the political claims for the rights to the city. This kind of public policy generates tensions among those who question the neo-liberal capitalist urbanization ways and express similar discourses about the rights to the city and housing. The political fragmentation occurs when habitus generating forces come into play to become the city the center of disputes. Thus, the ethnic dimension of the habitus revels the racist component of the gentrification.
\end{abstract}

Keywords: gentrification; ethnic habitus; Curitiba; urbanism; Brasil 
$\mathrm{L}$

a acción colectiva ligada al derecho a la ciudad suele presumirse como homogénea, donde todos los actores involucrados comparten ciertas condiciones sociales. Sin embargo, analizadas a escala microsocial estas prácticas aparecen diferenciadas por lo que Bourgois y Schonberg (1999: 75) denominan "habitus étnico". Así, entre los distintos movimientos críticos al capitalismo global, que luchan por el acceso urbano, existen diferencias de clase, étnico-raciales y sexo-genéricas. La investigación desarrollada da cuenta de las dos primeras frente a la "revitalización" 2 de la calle São Francisco en la ciudad de Curitiba (Paraná), en Brasil.

Este trabajo se propone mostrar a través de un análisis relacional las tensiones sociales que suponen los procesos de gentrificación, incluso para aquellos que cuestionan las formas de urbanización del capitalismo neoliberal. En general, estas disputas son examinadas en tanto antagonismo entre los movimientos sociales y el Estado como ejecutor, o facilitador, de la especulación inmobiliaria e intereses financieros. Este artículo coloca la mirada en otro aspecto: cómo los procesos de gentrificación fragmentan las luchas políticas generando disputas entre actores que manifiestan consignas semejantes y se expresan por el "derecho a la ciudad", pero que se encuentran atravesados por la distinción marcante de la dimensión étnica del habitus que reproduce las estructuras de poder simbólico que le dan sentido, distinguiendo entre aliados y enemigos políticos de la gentrificación y revelando el componente higienista de la misma.

\section{El caso de la "Rua do Fogo" en Curitiba}

En el año 2007 se lanza la "revitalización” del centro de la ciudad Curitiba3, capital del Estado de Paraná, que incluyó el circuito denominado "histórico" con miras a la realización del mundial de fútbol de 2014, donde la ciudad fue sede. Este proyecto de "revitalización" y seguridad urbana4 abarcó varias calles del centro, entre ellas una muy particular y pintoresca: la Rua São Francisco o "Rua do Fogo". Esta calle se caracteriza por su mística outsider, lo cual permitió construir un relato que atrajo tanto al turismo como a jóvenes hípsters que, como demuestran varios autores (LEES Y OTROS, 2008; WACQUANT, 2010; SMITH, 2012; FERNÁNDEZ, 2014), en la mayoría de las ciudades del mundo representan los principales colonos urbanos de la gentrificación.

Los fines civilizatorios y moralizadores fueron claros desde el inicio de la "revitalización”. El IPPUC5 describía así el proyecto:

Proyecto municipal quiere centro "civilizado": Según el administrador de la Regional Matriz, Omar Akel, el proyecto para las calles Riachuelo y San Francisco va a "domesticar" la región, disminuyendo los espacios para estacionamiento para volver al concepto de "centro histórico de ciudad civilizada" (...) Otra de las acciones esperadas para los próximos meses es una cierta "moralización” del área, donde hoy en día hay un cine

\footnotetext{
${ }^{2}$ Categoría nativa del poder público que ha sido apropiada por la prensa, comerciantes y vecinos.

3 Curitiba es una ciudad considerada "modelo" por su tradición de planificación urbana. Olivera (2011) analiza ese proceso como una alianza entre el poder público y el capital económico local que permitió el desarrollo de la política urbana. Entiende que Curitiba constituye un modelo de ciudad capitalista.

4 La reforma emprendida en Brasil a partir de los llamados "mega eventos" incluyó al urbanismo como parte fundamental del programa de seguridad pública "integral", y las fuerzas de seguridad cumplieron un rol preponderante custodiando las fronteras urbanas (CRAVERO, 2020)

5 Instituto de Planeamiento Urbano de Curitiba (IPPUC de ahora en adelante)
} 
porno, puntos de prostitución y tráfico de drogas. (GAZETA DO POVO 18/07/2009 disponible on line en: https://www.gazetadopovo.com.br/economia/riachueloquer-recuperar-brilho-bql39ut49xhd993fyxwzintii/ Traducción de mi autoría).

Este plan que asumía la posibilidad de convertir un espacio “degradado" por la droga y el sexo, en una calle "civilizada", expulsando aquellos considerados "inmorales", mantuvo su continuidad a través de las gestiones municipales comprendidas en el período 2011 - 2015, y significó la definición de ciertos patrones de interacción social a partir de la política urbana 6 . Para el caso analizado, el proceso de gentrificación asume características higienistas, que responden a la "estructura socio-urbana" (CASTELLS, 2014: 139) de Curitiba, así como a la historia social del Brasil, donde algunos grupos sociales son considerados sus antagonistas "naturales". Se trata de la población "superflua" del capitalismo global: adictos sin techo, prostitución de calle y el pequeño tráfico de drogas en la vía pública (BAUMAN, 2005: 14). Además de esta cuestión, el caso de la Rua São Francisco en Curitiba pone en evidencia la existencia de movimientos sociales aliados a la gentrificación, y movimientos sociales enemigos políticos del proceso. Sin bien, ambos encuentran la argumentación de su existencia en la lucha por el "derecho a la ciudad", unos serán integrados y otros reprimidos. Dentro de los primeros encontramos al ciclo-activismo, y como parte de los segundos aparecen los okupas vinculados al MTST7.

\section{El ciclo-activismo y las clases creativas de Curitiba}

Durante el período estudiado (2014 - 2017) el ciclo activismo curitibano se conformaba por el Movimiento Ciclo Iguaçu y la Bicicletaria Cultural. Ambos encuentran raíz en un grupo de artistas e intelectuales que se manifiestan a favor de la libre circulación, el uso de la bicicleta, el derecho a la ciudad a través de las intervenciones artístico / culturales y la sustentabilidad ambiental en contextos urbanos:

É.... eu acho que como eles viram... como eles tem um olhar já treinado pra intervenções urbanas, tem vários artistas plásticos envolvidos também no movimento, né? A Ciclo Iguaçu surge, o germe da Ciclo Iguaçu, pelo menos isso aparece na narrativa... na retrospectiva que eles fazem... com um grupo de artistas individuais. (Referente del Movimiento Ciclo Iguaçu y constructor de la Praça de Bolso do Ciclista, en entrevista concedida a la autora)

A bicicletaria não é uma $O N G^{8}$. Ela dialoga com o nosso background que é das artes. A história tem a ver com o teatro e as artes plásticas. Iniciou em 2005-6 com o coletivo artístico interlux, vinculado á bicicleta, participou de Festival de arte visual e arte bici-movil. Depois em 2011 (...) se deu a conclusão séria, organizada, da Ciclo Iguaçu. Foi maio de 2011 e em agosto surgiu a bicicletaria, como movimento irmão. (Registro de campo. 4/09/2015) 9

Si bien la organización del ciclo-activismo es reciente, representa un movimiento fuerte dentro de la ciudad, con varios años de militancia, contando incluso con referentes políticos locales y participación electoral a través de diversas fuerzas partidarias. Fue precisamente este movimiento el que se convirtió, desde la sociedad civil, en el principal aliado del poder público para gentrificar la Rua São

\footnotetext{
${ }^{6}$ Es importante destacar, que, a raíz de una serie de ciclos comerciales, así como nuevas gestiones políticas en la ciudad, la calle se encuentra nuevamente en un período de "abandono". Sin embargo, el plan de "recuperación" del centro continúa presente, convirtiéndola en tierra fértil para la especulación.

7 Movimiento de los Trabajadores Sin Techo de Brasil (MTST en adelante).

8 Organización No Gubernamental (ONG en adelante).

9 Todas las citas que impliquen la "voz" de los sujetos de investigación (oralidad) se mantendrán en su lengua original, en este caso el portugués, sin traducción y se colocaran en cursiva. Esto responde a la tradición socio-antropológica que se desprende de la perspectiva relacional asumida.
} 
Francisco. El hito que marcó dicha alianza fue la construcción de una pequeña plaza que denominaron Praça de Bolso do Ciclista ${ }^{10}$.

En 2014, y como parte de la "revitalización", el municipio cedió al movimiento un terreno erigido en las intersecciones de la Rua São Francisco y la Rua Presidente Farias, en pleno centro de Curitiba, para la construcción de la plaza que fue inaugurada el día mundial sin automóvil, el 22 de septiembre de 2014, con la presencia del entonces intendente. La placita se construyó de manera colaborativa ${ }^{11}$ frente a un edificio que registraba 20 años desocupado.

Resulta imposible entender la gentrificación de la Rua São Francisco dispensando la presencia de la praça y su relación con la bicicleta. Si bien los/as cicloactivistas le dieron una impronta propia, ya que desde el poder público se había planeado una intervención orientada al concepto de smart city, es indudable que la iniciativa contribuyó de manera efectiva con los planes moralizadores y civilizatorios para la región. Por otra parte, a partir de dicha alianza revitalizadora existieron beneficios comerciales y políticos ${ }^{12}$ para algunos integrantes del cicloactivismo.

La praça, vinculada al movimiento Ciclo Iguaçu y Bicicletaria Cultural, significó la atracción de un determinado público a la São Francisco: los llamados creativos/as. Esto le permitió a la calle tener su período de esplendor, especialmente de ocio nocturno, entre 2014 y $2015^{13}$.

Para entender cómo operan las fuerzas generadoras del habitus étnico en el contexto de las estructuras socio-urbanas, fue necesario construir algunos datos socio-demográficos sobre quiénes constituyen, en términos sociológicos, las “clases creativas". Este último es un concepto de Richard Florida (2000), quien, a partir de la realidad de los países del capitalismo avanzado, como los Estados Unidos, establece una correlación entre desarrollo regional con la presencia de arquitectos, diseñadores, músicos, profesores/as universitarios, cuya función económica es crear nuevas ideas, tecnologías o contenidos culturales. Hasta tal punto resulta relevante la presencia de este sector social para el avance del capital en el espacio urbano, que Florida (2000) constata, para el caso de los EE. UU. 14, que las empresas emigran tras esta mano de obra y no a la inversa, como solía acontecer en un esquema industrial clásico. Para el autor esto significa el surgimiento de un nuevo sector socioeconómico, concebido como motor de crecimiento en la actual fase del capitalismo en las ciudades.

Como se observa en los fragmentos de entrevistas citados en el apartado anterior, las artes se encuentran en la génesis misma del ciclo-activismo curitibano. Sin embargo, en situación de entrevista no quedaba clara la posición de estos artistas en la estructura socio-urbana. Así, fue necesario construir algunos indicadores más concretos. Para ello se aplicó un cuestionario survey a través de las redes sociales, entre personas autodenominadas "amigos de la Rua São Francisco", que compartían en el algoritmo de preferencias identificación con los grupos de ciclo-movilidad.

\footnotetext{
10 La palabra portuguesa "bolso" refiere al bolsillo en español. Esta denominación fue escogida para dar cuenta de lo pequeña que es la plaza, siendo además uno de sus principales encantos y atractivos.

${ }^{11}$ El registro de dicha experiencia puede verse en el documental disponible en https://vimeo.com/122463936

${ }^{12}$ Los mismos no son explicitados por ninguno de sus miembros en situación de entrevista, representando casi un tabú a la hora de producir discursos públicos. Sin embargo, miembros del movimiento eran dueños de un local gastronómico, y otro fue candidato a "vereador" (concejal) en las elecciones de 2014.

${ }^{13}$ Esto se encuentra registrado en el trabajo de tesis a través de diferentes técnicas, tanto de corte cualitativo como cuantitativo: observación participante, registro fotográfico, entrevistas e incluso cuestionario survey. Por razones de extensión su presentación se encuentra acotada en este artículo.

14 Estados Unidos de América (EE. UU. en adelante).
} 
Los datos más relevantes construidos en relación a la "revitalización" de la Rua São Francisco, arrojaron que a partir de la presencia de la praça e intervención del movimiento ciclo-activista, el 39,5\% de los frecuentadores y consumidores del corredor gastronómico de la calle registraban formación de posgrado; el $32,4 \%$ estudios universitarios completos; el 23,9\% universitario incompleto y el 4,2\% secundaria completa (Datos propios. Survey, 2015). Es decir, se trataba principalmente de personas con alto nivel educativo. Esto debe considerarse en relación al hecho de que el 81,7\% declaró "no tener hijos/as"; el 68,9\% se definió "soltero/a"; el 59,2\% residía con el grupo familiar y que el promedio de edad de aquellos/as que respondieron el cuestionario era de 31 años. (Datos propios. Survey 2015). Es decir, se trataba de los hijos e hijas de las tradicionales clases medias y clases medias-altas blancas, ya que el 77,1\% señaló que así lo era su color de piel, registrándose un 10,2\% como pardos y sólo un 4,7\% negros (Datos propios. Survey, 2015). Es decir, que los creativos/as vinculados al ciclo-activismo de Curitiba, que ocuparon la calle en el período 2014-2015, eran fundamentalmente blancos/as educados/as, pertenecientes a las tradicionales estructuras socio-urbanas.

Fue necesario construir estos datos y asentarlos de manera cuantitativa, porque resultaba muy difícil su registro con la técnica de entrevista. La mayoría de estos/as jóvenes no se asumen como privilegiados/as. Esto se explica a través de lo que Walter Mignolo (2004) llama “izquierdas epistémicas”, es decir, posiciones progresistas adquiridas a través del conocimiento, pero no a partir de la dis-posición o corporeidad. En términos metodológicos, cuando se trata de dichos sujetos de estudio, resulta difícil registrar cualitativamente la posición en la estructura socio-urbana, ya que explicitar las condiciones materiales de existencia es vivenciado como incoherencia ideológica. Por este motivo, con dicha población resultó más efectivo el uso de técnicas cuantitativas.

\section{La "periferia" okupa"}

Cuando el poder público de Curitiba asumió "la cultura" como retórica en torno a la "revitalización" de la Rua São Francisco y facilitó la construcción de la praça, sectores sociales "periféricos", afines a la música hip hop y rap, se sintieron interpelados y lo tomaron como una posibilidad de participación. Así, la llamada "periferia" 16 comenzó a participar del ocio nocturno de la calle.

Con la llegada de la juventud del área metropolitana se conformó un movimiento cultural de la calle São Francisco con dos expresiones marcadas: por un lado, el ciclo-activismo anteriormente descrito, y, por otra parte, la OCEL ${ }^{17}$, afiliada a la cultura hip hop y a prácticas urbanas de "resistencia política" y "ocupación”. En octubre de 2014 un grupo de diez personas sintecho (entre ellos artistas) ocuparon un inmueble de unos 14 pisos que había permanecido abandonado por 20 años, propiedad de la constructora Weber, y localizado exactamente en el mismo terreno que la Praça de Bolso do Ciclista, en el comienzo de la Rua São Francisco, esquina con la Rua Presidente Farias.

\footnotetext{
${ }^{15}$ Se utiliza la palabra "okupa" para dar cuenta de la lucha política por el derecho a la vivienda simbolizada en el movimiento global de dicho nombre. En el caso estudiado las personas registraban afiliación política con el MTST y Partido Comunista de Brasil.

${ }^{16} \mathrm{El}$ mito de la "democracia racial" curitibana (MORAES Y GARCIA DE SOUZA, 1999) implicó una marcada división territorial, el centro ha sido históricamente reservado a la Curitiba racializada blanca - europea, definida en oposición a la Curitiba racializada no-blanca periférica.

17 Ocupação Cultural Espaço de Liberdade (OCEL de ahora en adelante).
} 
La Ocupación se emplazó en un edificio que llevaba 20 años deshabitado sin establecerse nunca de manera cierta los motivos18 y que es todo un ícono en el imaginario curitibano, ya que se trata de un inmueble de grandes dimensiones, emplazado en el centro de la ciudad, en una de las Avenidas más transitadas. Debido a la cantidad de tiempo que lleva desocupado, quedó asociado en el imaginario de la población al uso de drogas (moco).

Los okupas representan una relación histórica con la tierra diferente a la de los/as creativos/as, y por lo tanto adquieren "otro" lugar en la estructura sociourbana brasileña. En ese entramado agencia - estructura, las experiencias narradas en forma biográfica permiten la reconstrucción de tramas de significación que evidencian los nexos entre la subjetividad y el contexto, permitiendo entender la historia social.

\begin{abstract}
Apesar de ser pobre, aquela coisa toda... E morar debaixo de lona... já morava debaixo de lona aquela época... que... a questão da terra sempre foi um grande problema no Brasil... Desde lá de trás, muito antes do movimento sem-terra, né? (...) já vinha a exclusão, a miséria... Depois da falsa libertação dos escravos, passou por processo de que o negro não tinha a... terras, não propriedade... os negros, né? Então eles passavam a ser mão de obra barata de novo, né? Então eles seriam escravos, não mais dos senhores de escravos, eles seriam escravos... mão de obra escrava dos... dos imigrantes, né? Que... que... e, eu vim dessa geração... lá atrás, eu vim do interior... trabalha na roça, muito cedo por conta da desestruturação familiar, eu fiquei sozinho já com dez, doze anos... dez anos, fiquei sozinho nesse período... E eu tinha que trabalhar por comida, então eu trabalhava o dia inteiro e ganhava um saquinho de feijão e um saquinho de cebola (...) eu sou descendente de... de quilombo, vamos dizer assim, remanescente de quilombo mas também com bastante característica cabocla, porque tem mistura de índio também a minha família... indígena... (Morador de OCEL, en entrevista concedida a la autora)
\end{abstract}

El lugar de enunciación responde a una confluencia de aspectos históricos del Brasil: el movimiento migratorio del campo a la ciudad, el gran problema de la tierra, y la cuestión étnico - racial, definida en una generación que es "remanente" de quilombolas, con características caboclas e indígenas ${ }^{19}$. Esto significa un sistema de parentesco caracterizado por abuelos que fueron personas esclavizadas. Por otra parte, la "falsa liberación" a la que hace referencia el entrevistado da cuenta que sus padres constituyeron la mano de obra barata de los inmigrantes. Esta descendencia se establece en la estructura socio-urbana como una posición definida en términos de dominación económica, pero también de resistencias.

El movimiento migratorio del campo a la ciudad, en conjunción con la concentración de la tierra, llevó al ámbito urbano los históricos reclamos del MST, donde el MTST será su heredero directo en la ciudad. Esta cuestión también es narrada en situación de entrevista:

Então foi baseado no que os valores que a minha família passou, eu cheguei na cidade
com valor, né? Eu não cheguei como uma pessoa sem valor, sabendo da dificuldade
da minha família [incompreensível] da moradia desde lá de trás... E cheguei pra ci-
dade, cheguei na rua... Morei em São Paulo, cheguei em São Paulo com dez, doze anos
de idade, São Paulo tinha... já quase naturalizado, que... que é quase um pertenci-
mento de casta... E aí você começa a estudar... Aliás, a própria ideia de Biblioteca
Pública... a primeira vez que eu entrei em uma biblioteca, pra mim era uma grande
coisa... Pra mim era privado, como uma propriedade privada... Porque lógico que eu

${ }^{18}$ Desde el discurso oficial se justifica la situación por "problemas estructurales en la construcción que lo tornaron inhabitable" ("o prédio esta torto"), y sin brindarse mayor información al respecto.

${ }^{19}$ Los quilombos en Brasil fueron territorios "libres" de personas que huían del sistema de explotación esclavista. En Brasil ser quilombola constituye una identidad reivindicada por movimientos sociales como el Movimento Negro, el Movimento sem Terra (MST en adelante) y el MTST. Por otro lado, la designación "Caboclo" se utilizaba en Brasil para designar la mixtura entre "blancos" e "indios". 
morava na rua, nós entrava em qualquer lugar que eles diziam público, nós era chutado lá de dentro pelos seguranças, né? Então eu tive uma grande dificuldade... muito tempo depois para entender o que que é público.... Então, público e privado para mim era a mesma coisa... então, a partir disso, quando a gente tava em São Paulo nos dias muito frio, a gente pensava "não, não podemos ficar na rua se não nós morremos"... Então... é uma percepção ideológica... E a gente começou... ocupar algumas casas, algumas...algumas garagens que ficavam... alguns barracão que ficavam abandonado. (Morador de OCEL, en entrevista concedida a la autora)

Las estructuras históricas asociadas a la concentración de la tierra en un modelo de acumulación colonial esclavista se ponen de manifiesto en estas trayectorias, que, de acuerdo con antecedentes revisados (CALDEIRA, 2000; FRANGELLA, 2009), representa la procedencia de un importante sector de la población sin techo en el Brasil.

La re-construcción de la experiencia okupa permite entender la ciudad atravesada por discursos normativos, que construyen la paradoja de una ciudadanía "natural", a la que le pertenece lo público, y "otros" que conforman el exterior de esa configuración, pero que a su vez resultan necesarios en su propia definición. El sector de la población que las políticas de la ciudad neoliberal tratan en forma de "residuo" marginal, conforman el "exterior constitutivo" (MOUFFE, 2007: 22) de los sectores acomodados de la modernidad capitalista. Esto significa que, por un lado, se vuelven necesarios para la definición identitaria de los establecidos, pero, por otra parte, es preciso que continúen en las márgenes como ese "otro" que queda fuera del espacio de iguales y asegura la permanencia de los establecidos en cuanto tales ${ }^{20}$. Así, se conforman las fronteras sociales y morales.

La OCEL simbolizó, en el caso de Curitiba, el sentido político de ocupar en la ciudad neoliberal. La constructora dueña del predio, declaró a la prensa local que los ocupantes se aprovecharon de una situación de colaboración que la empresa tuvo con el ciclo-activismo, cuando le permitieron guardar materiales utilizados para la construcción de la Praça do Bolso do Ciclista: "Abrimos el inmueble para que la gente guardara los materiales de construcción. En ese momento ellos se infiltraron, se instalaron y no quieren salir" (GAZETA DO POVO, 3/5/2015. Disponible on line http://www.gazetadopovo.com.br/caderno-g/ocupacao-em-predio-apimentaa-discussao-d62angkizkirvzlpnspbchm7w Traducción de mí autoría). El desalojo y restitución fue exigida por la propia empresa constructora que lo mantiene des-habitado, y se realizó con presencia de la Policía Militar en el lugar, el 8 de mayo de 2015 .

La OCEL fue una ocupación abierta a la comunidad a través de diferentes actividades culturales. Las diez personas que allí vivían producían en huertas orgánicas y eran gente sin vivienda, desocupados, proveniente de la región metropolitana de Curitiba, de la "periferia". Desde OCEL se responsabiliza de la situación al grupo de la Bicicletaria Cultural, en el sentido de ser quienes radicaron la denuncia formal para que la policía pudiera proceder a desalojar: "quem foi testemunhar contra nós ... foi o pessoal da bicicletaria... O R. da bicicletaria... e o Location, né?" (Morador de OCEL, en entrevista concedida a la autora).

Sin embargo, frente a la pregunta de quiénes estaban fastidiados con la presencia de los "sin techo" en la región, identifican una red de complicidades político-económicas atravesada por la lucha de clase y la disputa por la ciudad:

${ }^{20}$ La categoría exterior constitutivo, basada en el concepto derridiano de différance, explica toda identidad a partir de la exclusión de una alteridad. El "otro exterior" aparece como necesidad afirmativa de cualquier identidad política colectiva construida como correlato de una diferencia. (MOUFFE, 2007: 22) 


\begin{abstract}
E: Primeiro, os grileiros ${ }^{21}$... as pessoas do prédio... essas pessoas que estavam no prédio... Procurador, mas acho que era muito maior que ele... Essas pessoas são... Nós sabemos que a nossa ocupação, o que ela representa, não só do ponto de vista econômico... Vamos dizer que aquilo ali, aquele terreno ali, vamos subestimar cinco milhões, dez milhões, não sei... Aquilo, né? Pedacinho... não sei... É [incompreensível] $P$ : Esta na área da revitalização?

E: É... uma (rua) (...) Mas esses caras eles são [incompreensível] porque eles vão fazendo as coisinhas, coisinha, coisinha... E nós temos que... eles tem que saber que a cidade é disputada... O (Largo da Ordem) é disputado por várias forças, territórios que disputam tanto o comércio, a economia comum, quanto a economia informal... $E$ essa é a verdade... Essa é uma verdade... (Morador de OCEL, en entrevista concedida a la autora)
\end{abstract}

Desde el discurso oficial se planteaba que el edificio no estaba en condiciones de habitabilidad y esto ponía en riesgo la vida de las personas que allí se encontraban. Estas cuestiones eran negadas por la ocupación, que interpreta el abandono del mismo en términos de especulación inmobiliaria, tal como puede leerse en la cita. Por otro lado, desde OCEL argumentaron haber realizado obras de mantenimiento y acondicionado el lugar para una "ocupación segura". Lo que sin dudas la OCEL puso de manifiesto fueron los intereses económicos detrás del discurso "cultural” y patrimonial de la "revitalización”, es decir la gentrificación con su lucha de clases y las diferencias sociales basadas en criterios étnico-raciales que se ponen de manifiesto al interior del movimiento cultural de la calle São Francisco cuando entran en juego las fuerzas generadoras del habitus que establecen los patrones de interacción.

\title{
La dimensión étnica del habitus
}

Habitus es un concepto central en la sociología de Pierre Bourdieu (1986, 2007), que ha tenido diversas (re)apropiaciones en trabajos posteriores, herederos de su perspectiva, como Loïc Wacquant (2004), para quien el habitus de Bourdieu tiene su génesis en la idea de hexis corporal desarrollada por Aristóteles; o Bourgois y Schonberg (1999) quienes lo reelaboran a partir de la tensión entre blancos y negros detectada en el trabajo empírico. Dentro de la propia teoría de Bourdieu (2007), el concepto ha tenido un devenir analítico, lo cual dificulta establecer una definición unívoca sin correr riesgos de cercenar su potencialidad explicativa. En términos generales, podemos decir que las estructuras de poder simbólico son definidas históricamente e in-corporadas disposicionalmente de manera relacional. Esto representa el habitus: una génesis social de esquemas de percepción, pensamientos y acciones que construyen una visión del mundo, y a su vez un modo de estar en él. El habitus es lo social internalizado, incorporado, en el sentido de hecho cuerpo, y a su vez naturalizado. Se trata de un principio organizador de prácticas y representaciones, que sólo puede comprenderse en relación con las estructuras de poder simbólico. Asumir el concepto de habitus significa entender "lo social" como experiencia vivida intersubjetivamente.

Investigando el caso de los heroinómanos sin techo en California, los autores Bourgois y Schonberg (1999) construyen el concepto de apartheid íntimo a partir de los patrones de interacción y la dimensión étnica del habitus:

Centramos nuestra atención en el estudio de las tensiones entre negros y blancos; y fue a partir de este enfoque que desarrollamos el concepto de "habitus étnico". Este último ayuda a comprender cómo las divisiones basadas en el color de la piel se acentúan con

${ }^{21}$ Resulta difícil traducir al español y explicar este término común en el Brasil. Designa la falsificación de documentos para hacerse con la propiedad de las tierras. En inglés se utiliza la expresión "Land Grabbing” para designar algo similar. 
la interacción diaria, produciendo un "apartheid íntimo" en un contexto de proximidad física e indigencia compartida. (BOURGOIS Y SCHONBERG, 1999: 66)

El apartheid íntimo es definido por un contexto de proximidad física y condiciones sociales compartidas, pero diferenciadas por cuestiones étnico-raciales ("habitus étnico") en cuanto marcadores sociales. Durante la investigación desarrollada el concepto de habitus étnico ${ }^{22}$ fue reelaborado de acuerdo con el contexto brasileño: en un ámbito de proximidad cultural (en el sentido de consumos culturales) y banderas políticas compartidas (derecho a la ciudad) que harían presuponer una lucha común frente a los procesos de gentrificación urbana, aparecen las divisiones basadas en los históricos marcadores socio-raciales del Brasil.

Ambos movimientos (Ciclo-activismo y OCEL) manifiestan intereses y preocupaciones "culturales", frecuentan espacios comunes, se autodefinen de "izquierda" y luchan por una ciudad más inclusiva. Esto haría presuponer una semejanza política, pero el conflicto evidencia las diferencias sociales y raciales que los atraviesan, localizándoles de manera desigual en la estructura sociohistórica y urbana. Durante la investigación fueron analizadas las estrategias de poder para hacerse con el espacio urbano como fuerzas generadoras del habitus étnico.

El 9 de marzo de 2017 se reaviva la polémica por la desocupación de la OCEL, y la atribución de responsabilidad vuelve a dirigirse al movimiento ciclo-activista. Este evento es quizás el que mejor grafica la diferenciación. Una de las voces de OCEL hace pública una denuncia de racismo y prejuicio que habrían sufrido él y su hija en las instalaciones de la propia Bicicletaria Cultural. Así lo relataba en un mensaje en las redes sociales, que circuló con pocas repercusiones durante un tiempo:

RACISMO Y PREJUICIOS EN LA BICICLETARIA CULTURAL. Relato: viernes o3 de marzo fui atropellado con la bicicleta cerca del shopping estación. Por suerte, y gracias a Dios, sólo se averió el neumático trasero y la rueda quedó trabada. Como actualmente estoy viviendo en la CIC - Ciudad Industrial de Curitiba- necesitaba un lugar para arreglar la bicicleta. El único taller que recordé fue el de Jean en la San Francisco - Centro, pero estaba cerrado. Entonces me acordé de otro taller justo enfrente: la bicicletería cultural de F, el mismo que fue a testificar en nuestra contra y a favor de la constructora durante la ocupación de la OCEL. Ante la falta de alternativas acabé sometiéndome a la afrenta de pedirle un servicio, quien recibió la bicicleta sin objeciones, para mi sorpresa. Sin embargo, hoy 9 de marzo, alrededor de las 16 h, y casi una semana después, llego al taller y la bicicleta estaba apoyada en el mismo lugar que la dejé. Percibiendo algo extraño en el aire, ni siquiera cuestioné la no realización del servicio al que se habían comprometido. Inmediatamente, y sin ninguna explicación, fui rodeado e insultado por el F., la P. y la hermana de la P. Acusándome de haber reclamado y de "hijo de puta", al mismo tiempo que el F. decía con todas las letras que aquel lugar no era para personas como yo. Entonces le pregunté ċué tipo de persona estaba refiriéndose? Fue entonces cuando de forma cínica y mala me dijo mirándome a los ojos: personas como vos, de tu tipo. Acto seguido pidió a los empleados que llamaran a la Guardia Municipal para retirarme del local por la fuerza. Fue en ese momento que sentí el carácter racista y prejuicioso de la situación, llamé al 190 e informé de lo ocurrido. El PM me preguntó si tenía testigos. Miré para los costados y me di cuenta que sólo estábamos yo, Dios y mi hija como testigos a mi favor. Todo negro que es discriminado sabe cuándo es víctima de un racista. Triste y choqueado por haber sido discriminado enfrente de mi hija, me sentí impotente y sin nada para hacer al respecto. Tomé la bicicleta rota y la llevé a otro taller. Tengo plena convicción de la necesidad de combatir el racismo, pero dadas las circunstancias no pretendo denunciar al F. por racismo, hasta porque él es un idiota antes que un racista, y también porque sé que las personas que frecuentan la bicicletería cultural forman parte del círculo cultural que también frecuento. (REGISTRO DE CAMPO. Comentario publicado en Facebook, 10/03/2017 Traducción de mí autoría)

22 Por coherencia teórica se respetó la designación original de Bourgois y Schonberg (1999), pero entendemos que, histórica y antropológicamente, la academia brasileña adopta la categoría raza y no etnia. De allí la re-elaboración del contenido de la categoría "habitus étnico" en términos locales, es decir, orientada a la cuestión racial. 
La última oración da cuenta de la escisión producida por la dimensión étnica del habitus en tanto marcador social. Existe un ambiente compartido, lugares comunes frecuentados, semejanzas que los atraviesa en cuanto consumidores culturales, sin embargo, unos representan la racialización negra de la periferia y otros la racialización blanca del centro, y se agruparán de acuerdo con esta división. Los primeros, constituyen un movimiento adverso a la gentrificación urbana, los segundos se transforman en aliados que contribuyen con su legitimación.

Por otra parte, el evento de la denuncia pone en evidencia las diferencias sobre las que se cimientan desigualdades sociales, materializadas en condiciones de vidas disímiles para unos y otros. Es decir, a pesar de compartir el mismo show musical, película documental en la cinemateca de Curitiba, o exposición de arte "alternativa", los ocupantes de OCEL nunca representarán para el poder concentrado la clase creativa de Curitiba en los términos esgrimidos por Richard Florida (2010). Es decir, unos/as constituyen históricamente la casa grande, otros/as la senzala ${ }^{23}$, aunque a veces los cuerpos se encuentren bailando al ritmo de Criolo ${ }^{24}$ en algún show, o en las filas de la misma manifestación política por el derecho a la ciudad.

\section{“Ocupar" e "Invadir": la dimensión étnica del habitus como marcador social}

En las estructuras de poder simbólico, las formas de estar y habitar el espacio se encuentran atravesadas por la dimensión étnica del habitus. Aquellos "indeseables" para la "revitalización", que constituyen un escollo en términos económicos y/o simbólicos, serán representados como "invasores" (no les pertenece), mientras los "deseables" son "ocupantes" (les corresponde por "derecho natural" - de clase y étnico-racial).

El conflicto originado por el edificio abandonado de la Weber Construcciones entre el movimiento ciclo-activista y la OCEL, pone de manifiesto estas cuestiones:

\footnotetext{
P: mas daí aconteceu alguma coisa, alguma tensão com a galera da bike né? ... E3: rolou, mas... eu não sei se tensão é exatamente a ideia e ai eu tenho a impressão que eu vou falar o que o Max me contou e eu sei que você provavelmente vai pensar nossa penso completamente o contrário... o Max me falou o seguinte: diferente da ocupação da praça que foi uma ocupação negociada com a Prefeitura e com o dono do terreno do prédio, a ocupação do prédio foi silenciosa no sentido que ninguém ficou sabendo nem a galera que estava envolvida com a praça nem o dono do terreno $P$ : foi de uma noite para um dia...

E3: é! Assim, o cara lá, como que é? O... D..

P: O DR aja!

E3: $O D R$, isso! Ele foi trazendo as coisas dele e foi meio que deixando quando a galera... O Max foi que me contou isso diz que quando eles perceberam, ele estava com um monte de coisas lá, ele meio que dormindo, falando que ia cuidar das coisas, que... Só que de repente, pois aquela placa lá da ocupação cultural não sei que... Não sei que... Então eles ficaram de cara... (Empleado de Bar de la Rua São Francisco, en entrevista concedida a la autora)
}

\footnotetext{
${ }^{23}$ En relación a la alegoría creada por el pensador brasileño Gilberto Freyre para dar cuenta del modo de organización social y política en el Brasil colonial. Se trata de un símbolo de la segregación racial en Brasil.

${ }^{24}$ Rapero brasileño con alta convocatoria. Su música es interesante en términos de gentrificación, ya que una expresión de las clases marginales como el rap, es consumida por sectores medios "prestigiando" dicha música, mientras los sujetos sobre los que ella versa continúan siendo marginalizados y asesinados por la policía.
} 
Esta conversación es reveladora en términos de los sentidos detrás de la acción cuando se trata del espacio público. Por un lado, el ciclo-activismo utiliza la palabra "ocupar" con un sentido político próximo a los discursos gentrificadores y muy diferente al de los okupas, ya que para llevar a cabo sus acciones negocia con la Prefeitura y el dueño del terreno. Este consenso del ciclo-activismo con el poder público y económico resulta antagónico para quienes viven la ocupación desde otra conciencia/corporalidad:

\section{P: Ninguém pediu permissão? \\ E: Não... eu não vou pedir permissão para ocupar... para eles... Eu não vou pedir permissão pra ocupar... Não vou pedir permissão pra ocupar... E ninguém precisa pedir permissão pra ocupar... Ninguém precisa... (Morador de OCEL, en entrevista concedida a la autora)}

Entonces, la “ocupación” de la Praça de Bolso do Ciclista y la del prédio abandonado de la Weber construcciones, representan dos formas diferenciadas por el habitus étnico de "ocupar el espacio público" entre aquellos/as que tienen voz para negociar e interpelar al poder público, porque son descendientes de las elites citadinas, y aquellos/as que han sido históricamente excluidos, descendientes de quilombolas, y cuyo vinculo principal con el Estado está signado por la criminalización y represión de las fuerzas de seguridad. En Brasil, no se puede dejar de lado la historia de esclavización al momento de analizar estos patrones de interacción y sopesar cuánto de segregación socio-racial co-existe de manera imbricada con la segregación espacial:

Eu ainda tenho problema de moradia... E o que vai me restar? A ocupação... (...) Ou eu pego um trabalho de um horário até tal horário... vou sacrificar parte da minha vida, né? Meu direito... dedicado só ao trabalho pra pagar aluguel, vou virar um escravo, e eu me nego... Sinceramente, prefiro voltar a morar na rua...Eu não preciso mais morar na rua, porque hoje na minha idade, eu... eu acho que tenho tantos outros lugares que você pode... ocupar e viver tranquilo... (Morador de OCEL, en entrevista concedida a la autora)

La noción de "invasión” también emerge coligada a la variable "drogas" como elemento diferenciador. Cuando en la Rua São Francisco se hace presente la "alteridad" periférica, dicha cuestión es patente. La asociación entre "periferia”, jóvenes y tráfico de drogas es casi automática. El cuerpo periférico/racializado negro es tachado de narcotraficante, y la violencia en la Rua São Francisco de la "revitalización" es asociada con esta presencia. A raíz de un intercambio de opiniones en las redes sociales sobre la llegada de los/as jóvenes de la "periferia", una comerciante de la calle se manifestaba de la siguiente manera:

Puedo hablar de la realidad que observo todos los días en la calle, esa periferia inocente que defendéis, venden, consumen y pelean por el control del tráfico de drogas, quisiera ver en tu calle, en la puerta de tu casa, si eres tan defensor de esos pobres inocentes y si los invita a tomar un café en tu cocina. El comercio de la región existe desde hace mucho, yo vivo en el área desde 2006, esto era un depósito de adictos al crack, vi muchas personas asaltadas, heridas, y muchos comercios robados, después vino la revitalización, el higienismo como vos le decís, y algunas cosas comenzaron a cambiar y mejorar, los comerciantes de la región no podemos ser responsables de la incompetencia del Estado y la policía (...) Los jóvenes pobres de la periferia nos amenazan, esconden la droga enfrente de nuestros comercios y pobre de vos si les decís algo, si los miras a esos pobres productos de la sociedad. El consumo de drogas es a la vista y vos defendéis eso en tu sopita de letras. Apoyo 100\% la acción de la policía en la calle y la advertencia sobre los pobrecitos de la periferia. (REGISTRO DE CAMPO. Post en Grupo de Facebook Rua do Fogo. 25/10/2015 Traducción de mi autoría.)

En Brasil existe una construcción del estigma a partir de los patrones de interacción: ser joven y habitante de "periferia" significa ser sospechado de traficar 
drogas (SOUZA Y BODE, 2014). Así, el cuerpo periférico será racializado en el sentido periferia/negro/narcotraficante. Esta cuestión es constatable en los datos referidos a letalidad policial y encarcelamiento: De acuerdo con el informe final de la Comisión de Investigación sobre asesinato de jóvenes del Senado Brasileño, en el año 2016, un total de 23.100 jóvenes negros de entre 15 a 29 años de edad fueron asesinados durante ese período. Esto representa 63 víctimas por día, es decir, un/a joven muerto/a cada 23 minutos. En correlato con lo anterior, el Fórum Brasileiro de Segurança Pública dictaminó que entre 2009 y 2013 las policías brasileñas mataron 11.197 personas en casos tipificados como "actos de resistencia”, es decir 6 muertes por día. Es importante destacar que dichos datos tienen carácter de sub-notificados, ya que algunos Estados no brindan información al Fórum. De acuerdo con el CNJ25 de Brasil, existen en este país 24.000 adolescentes en situación de "privación de la libertad", el 57,41\% de ellos son negros o "pardos". De la población carcelaria total, el 61\% son racializados no-blancos ("pretos o pardos”), siendo el tráfico de drogas el crimen que más conduce al encierro carcelario (INFOPEN, 2014).

En el caso de la Rua São Francisco el recrudecimiento de la presencia y acción policial apareció conjuntamente con la llegada de la periferia/negra al lugar, que es asociada con el tráfico, estableciendo una ofensiva que da cuenta de lo que Judith Butler (2002) denominó cuerpos que importan y lo que no: los/as racializados/as blanco/centro, herederos de una posición privilegiada en la historia colonial definitoria de la estructura socio-urbana, aparecerán como consumidores, que además exigen su derecho a la libertad de consumo, mientras los cuerpos racializados negros/periferia serán sospechados de traficantes, y por lo tanto criminalizados, y aniquilados en el marco de la "guerra a las drogas" instalada en las ciudades brasileñas.

La racialización implica que mientras unos son considerados "ocupantes" naturales del espacio público, aquella ciudadanía que es y se siente interpelada por el poder público cuando llama a "ocupar" la calle, otros son considerados "invasores", aquellos que deben ser "limpiados" de las calles para la seguridad de los primeros.

\section{Reflexiones finales}

La gentrificación en Brasil se encuentra atravesada por una formación social dominante de raigambre colonial/esclavista, donde el saneamiento fue clave en la conformación de una burguesía local, racializada blanca, de la cual es heredera la actual clase media que actúa como nuevo "colono urbano", apropiándose de los espacios. Analizar el conflicto social desatado por la gentrificación en calve relacional contribuye a la desmitificación del ideal de "democracia racial" en el imaginario curitibano.

Curitiba representa un caso de nuevo colonialismo urbano higienista, donde la capital es hija de la "ciudad laboratorio" de la dictadura (OLIVEIRA, 2011: 15) y nieta de la modernidad colonial capitalista, donde el blanqueamiento fue posible gracias a la implementación del urbanismo como dispositivo de "limpieza" social, y que actualmente encuentra una letal combinación para los jóvenes racializados negros de periferia (CRAVERO, 2020).

El centro de la "ciudad modelo" del Brasil posiblemente constituya una de las últimas fronteras urbanas a ser conquistadas por el poder económico. Los okupas representan para los intereses concentrados un obstáculo a la gentrificación que 
los convertirá en sus adversarios políticos, porque minan las bases materiales de la misma y ponen en evidencia los beneficios económicos detrás de los discursos culturalistas y patrimonialistas, pero a su vez ellos son quienes ponen en evidencia las tensiones sociales y étnico - raciales dando cuenta de las fuerzas generadoras del habitus que se disputan la ciudad a través de diferentes maneras de "ocupar" y habitar el espacio público.

Con la reconstrucción de los patrones de interacción se pudo identificar la relación de los distintos grupos con el poder público y el capital inmobiliario-financiero que interviene en las definiciones de aliados y enemigos, así como la relación socio-histórica en una estructura urbana donde prevalecen jerarquías sociales y morales basadas en criterios raciales a la hora de definir el acceso a la ciudad.

Las formas de ocupar el espacio están atravesadas por la dimensión étnica del habitus en cuanto marcador social. Así, existen personas que impelidos de negociar con el poder público por complejos procesos de criminalización, y en base a exclusiones sociales, "ocupan” por necesidad. Por otro lado, existen grupos aliados que "ocupan" a partir de influencias con el poder y capital simbólico. La Praça de Bolso do Ciclista y el edificio abandonado por la Weber Construcciones representan dos formas diferenciadas por el habitus étnico de "ocupar" el espacio público. Los primeros simbolizan aquellos/as que tienen voz para negociar e interpelar al poder público, mientras la OCEL son los históricos excluidos de la tierra a través de la racialización/negra de sus cuerpos, y cuyo principal vínculo con el Estado está signado por la criminalización y represión de las fuerzas de seguridad.

En Brasil la fragmentación urbana responde a una re-actualización del proyecto colonialista de características higienistas que prevaleció en el siglo XIX. El caso analizado visibiliza este componente racista, así como las formas que adquiere en la coyuntura actual del capitalismo global, donde la segregación socioespacial y el problema habitacional de las metrópolis latinoamericanas resultan expresiones de la segregación racial.

Recebido em 24 de agosto de 2020. Aceito em 25 de novembro de 2020.

\section{Referencias}

BAUMAN, Zygmunt. Vidas desperdiciadas. La modernidady sus parias. Barcelona: Paidós, 2005.

BOURDIEU, Pierre. O poder simbólico. Rio de Janeiro: Difel, 1989.

BOURDIEU, Pierre. El sentido práctico. Buenos Aires: Siglo XXI, 2007. 
1986.

BOURGOIS, Philippe, SCHONBERG, Jeff. Apartheid íntimo: Dimensiones étnicas del habitus entre los heroinómanos sin techo. Revista Pensar. Epistemología, política y ciencias sociales, 3 (4): 66-90, 2009.

BUTLER, Judith. Cuerpos que importan. Sobre los límites materiales y discursivos del "sexo". Buenos Aires: Paidos, 2002.

CALDEIRA, Teresa P. R. Cidade de Muros: Crime, Segregação e Cidadania em São Paulo. São Paulo: Editora 34/Edusp, 2000.

CASTELLS, Manuel. La cuestión urbana. Buenos Aires: Siglo XXI, 2014.

CASTILHO, Cristiano. Ocupação em prédio apimenta a discussão. Disponible en https://www.gazetadopovo.com.br/caderno-g/ocupacao-em-predio-apimentaa-discussao-d62angkizkirvzlpnspbchm7w/ ,2015, Acceso: 14/8/19

CONSELHO NACIONAL DE JUSTIÇA. (2017) Disponible em http://www.cnj.jus.br/. Acceso 1/8/2017.

CRAVERO, Carolina. El urbanismo como dispositivo de control, vigilância y segregación. Revista Espaço Público, 5 (5): 1-21, 2020.

DE OLIVEIRA, Reinaldo J.; DE SOUZA OLIVEIRA, Regina M. Origens da segregação racial no Brasil. Amérique Latine Histoire et Mémoire. Les Cahiers ALHIM [En línea], 29: 2015, disponible en http://journals.openedition.org/alhim/5191.

FERNANDEZ GONZALEZ, Miquel. Matar al Chino. Entre la revolución urbanística y el asedio en el barrio del Raval de Barcelona. Barcelona: Virus Editorial, 2014.

FLORIDA, Richard. La clase creativa. La transformación de la cultura del trabajo y el ocio en el siglo XXI. Barcelona: Paidós, 2000.

FÓRUM BRASILEIRO DE SEGURANÇA PÚBLICA. Brasil. Disponible en http://www.forumseguranca.org.br/estatisticas/introducao. Accesso: 1/8/2017

FRANGELLA, Simone M. Corpos urbanos errantes. Uma etnografia da corporalidade de moradores de rua em São Paulo. São Paulo: Annablume Fapesp, 2009.

LEES, Loreta; SLATER, Tom; WILY, Elvin. Gentrification of central neighborhoods: a process in expansion and mutation. New York: Routledge-Taylor \& Francis Group, 2008.

LÜCKMAN, Andrè; ROMAGNOLLI, Luciana. Riachuelo quer recuperar brilho. Disponible en: https://www.gazetadopovo.com.br/economia/riachuelo-quer-recuperar-brilho-bql39ut49xhd993fyxwzintji/ 2009 Acceso 01/01/2017.

MIGNOLO, Walter. "Os esplendores e as misérias da "ciencia", colonialidade, e geopolítica do conhecimento e pluri-versalidade epistêmica". In: SANTOS, B.S. (org) Conhecimento prudente para uma vida decente. São Paulo: Cortez Editora, 2004. pp. 667-710.

MORAES, Pedro Rodolfo B. y GARCIA DE SOUZA, Marcilene. Invisibilidade, preconceito e violência racial em Curitiba. Revista de Sociologia \& Política, 13 (13): 7-16, 1999.

MOUFFE, Chantal. En torno a lo político. México: FCE, 2007.

OLIVEIRA, Dennison. Curitiba e o mito da cidade modelo. Curitiba: Editora 
UFPR, 2011.

SMITH, Neil. La nueva frontera urbana: ciudad revanchista y gentrificación. Madrid: Traficante de sueños, 2012.

SOUZA, Aknaton T. y BODÊ, Pedro Rodolfo M. Os perigosos: uma análise da construção do usuário de drogas como inimigo da ordem pública. Monografia, Sociologia, UFPR, 2014.

TERRA DE DIREITOS. Integrantes de Ocupação Cultural no Centro de Curitiba são despejados após ação de reintegração de posse. Disponible en http://terradedireitos.org.br/noticias/noticias/integrantes-de-ocupacaocultural-no-centrode-curitiba-sao-despejados-apos-acao-de-reintegracaode-posse/17653. $\quad 2015$, Acceso: 14/8/19.

WACQUANT, Loïc. "Habitus". In: BECKERT, J.; ZAFIROVSKI, M. (org.). International encyclopedia of economic sociology. Londres: Routledge, 2004. pp. 315-319.

WACQUANT, Loïc. Ressituando a gentrificação: a classe popular, a ciência e o Estado na pesquisa urbana recente. Cadernos CRH, 23 (58): 51-58, 2010. 